\title{
Khat use and psychotic symptoms in a rural Khat growing population in Kenya: a household survey
}

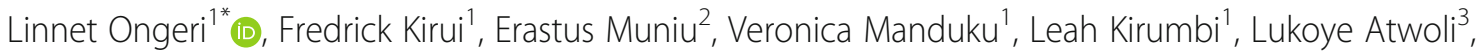
Safari Agure ${ }^{2}$, Peter Wanzala ${ }^{2}$, Lydia Kaduka², Mercy Karimi², Richard Mutisya ${ }^{2}$, Elizabeth Echoka², Joseph Mutai², David Mathu ${ }^{2}$ and Charles Mbakaya ${ }^{4}$

\begin{abstract}
Background: Khat is an amphetamine like psychostimulant chewed by over 10 million people globally. Khat use is thought to increase the risk of psychosis among its chewers. The evidence around this however remains inconclusive stemming from the scanty number of studies in this area and small study sample sizes. We undertook a large household survey to determine the association between psychotic symptoms and khat chewing in a rural khat growing and chewing population in Kenya.

Methods: For this cross-sectional household survey, we randomly selected 831 participants aged 10 years and above residing in the Eastern region of Kenya. We used the psychosis screening questionnaire (PSQ) to collect information on psychotic symptoms and a researcher designed sociodemographic and clinical questionnaire to collect information on its risk factors. We used descriptive analysis to describe the burden of khat chewing and other substance use as well as rates and types of psychotic symptoms. Using a univariate and multivariate analyses with $95 \%$ confidence interval, we estimated the association between khat chewing and specific psychotic symptoms.

Results: The prevalence of current khat chewing in the region was at $36.8 \%(n=306)$ with a male gender predominance (54.8\%). At least one psychotic symptom was reported by $16.8 \%(n=168)$ of the study population. Interestingly, psychotic symptoms in general were significantly prevalent in women (19.5\%) compared to men (13.6\%) $(p=0.023)$. Khat chewing was significantly associated with reported strange experiences $(p=0.024)$ and hallucinations $(p=0.0017)$, the two predominantly reported psychotic symptoms. In multivariate analysis controlling for age, gender, alcohol use and cigarette smoking, there was a positive association of strange experiences (OR, $2.45 ; 95 \% \mathrm{Cl}, 1.13-5.34)$ and hallucination (OR, 2.08; 95\% C.I, 1.06-4.08) with khat chewing. Of note was the high concurrent polysubstance use among khat chewers specifically alcohol use (78.4\%) and cigarette smoking (64.5\%).
\end{abstract}

Conclusions: Psychotic symptoms were significantly elevated in khat users in this population. Future prospective studies examining dose effect and age of first use may establish causality.

Keywords: Khat, Psychotic symptoms, Sub Saharan Africa, Kenya, And household survey

\footnotetext{
* Correspondence: linongeri@gmail.com

${ }^{1}$ Kenya Medical Research Institute, Centre for Clinical Research, P.O. Box

54840 00200, Off Mbagathi Road, Nairobi, Kenya

Full list of author information is available at the end of the article
}

(c) The Author(s). 2019 Open Access This article is distributed under the terms of the Creative Commons Attribution 4.0 International License (http://creativecommons.org/licenses/by/4.0/), which permits unrestricted use, distribution, and reproduction in any medium, provided you give appropriate credit to the original author(s) and the source, provide a link to the Creative Commons license, and indicate if changes were made. The Creative Commons Public Domain Dedication waiver (http://creativecommons.org/publicdomain/zero/1.0/) applies to the data made available in this article, unless otherwise stated. 


\section{Background}

Catha edulis, commonly known as khat, is a psychostimulant plant used by over 10 million people daily, mainly in eastern Africa and the Middle East [1]. Historically, khat was recognized as a ceremonial plant in Kenya, chewed primarily by older men during special social gatherings [2]. Recently however, the pattern of khat consumption has been slowly changing with not only a rise in use among women and the youth but also an increase in quantity of khat chewed [3, 4]. In addition to its longstanding traditional value, the sale of khat is an important contributor to Kenya's economy. Khat is currently Kenya's highest valued horticultural export accounting for about $60 \%$ of the total value of such exports [5]. It is mainly cultivated in the Eastern part of Kenya and its use remains legal in the country.

Khat is primarily ingested by chewing. The leaves and stalks of the khat plant are slowly chewed to release its juice which is then ingested with saliva. The residual pulp is subsequently pushed to the side of the cheek and the mouth continuously filled with fresh leaves. The accumulated ball of residue is eventually spat out at the end of the chewing session [6]. In addition to its euphoric acute effect, khat users also commonly report increased levels of alertness, decreased hunger and fatigue and a general sense of wellbeing during chewing [6-8]. The euphoric effect is felt within $1 \mathrm{~h}$ of chewing khat. Cathinone which is the main alkaloid constituent of khat reaches peak plasma levels $1.5-3.5 \mathrm{~h}$ after the onset of chewing $[9,10]$. Its average elimination half-life is four and half hours [11]. The acute effects of euphoria and alertness are later proceeded by excessive feelings of anxiety and irritability, poor concentration and insomnia following chewing [12]. The tolerance level of khat is low and withdrawal symptoms linked to khat use include nightmares, tremors, depression, sedation and hypotension $[13,14]$. Chronic khat use has additionally been linked to cardiovascular, digestive, genitourinary, endocrine and oral dental health problems [15-19].

On average $100 \mathrm{~g}$ of fresh khat leaves contain 36mgs of cathinone, $120 \mathrm{mg}$ cathine and $8 \mathrm{mg}$ norephedrine [20]. Khat is chewed for its psychoactive effect is thought to come from two phenylalkylamines; cathinone and cathine, which are structurally related to amphetamine [21]. Despite notable progress having been made in identifying the pharmacological basis of Khat there is divided opinions on the potency and subsequent neurobehavioral effects. Khat's effect on the central nervous system is thought to act like amphetamine by increasing the activity of the dopaminergic and noradrenergic transmission. [22]. Previous studies have shown associations between heavy khat use with psychosis and mania [23]. In addition, some studies have pointed towards khat exacerbating or triggering primary psychotic disorders such as schizophrenia [24, 25]. Khat induced psychosis has been described as transient in nature and characterized majorly by symptoms of paranoia and mania [26-28]. However, this research is non-conclusive and primarily based on case reports [29]. Another limitation to previous khat research is the number of neurobehavioral studies focused on highly traumatized migrant populations making findings inconclusive as to whether the trauma or the khat triggered the psychosis [30]. A deeper understanding of the epidemiology of khat associated psychosis is warranted to contribute to the evidence base necessary in developing policies around this plant. In addition, previous local community based studies have shown relatively high rates of participants endorsing at least one psychotic symptom (13.9\%) [31], being able to tease out the burden of psychotic symptoms attributable to khat use as compared to other risk factors is key to understanding khat use pathophysiology. Khat remains a controversial plant with differing opinions on its benefits and negative impact on human health [32], hence as part of the Kenyan government's efforts to understand the burden of khat use and its effects on human health we were tasked to conduct a large, population based study in a rural non migrant population of mainly khat growers. We report here findings on the prevalence of khat use and its association with psychotic symptoms in the survey population.

\section{Methods \\ Study design}

We used a cross sectional study design to collect data from randomly selected households.

\section{Study population and setting}

We conducted this study in Meru and Embu County situated in the Eastern Part of Kenya. The two counties border each other and together occupy close to $10,000 \mathrm{~km}^{2}$. These are the largest khat growing regions in Kenya and only second to Ethiopia in Africa.

The population of Embu County is estimated at 543,221 while Meru County population currently stands at $1,400,000$. The two communities are agrarian with a focus on cash crop cultivation this primarily being khat. The khat variant grown in Embu is referred to as Muguka while the Meru variant is known as Miraa. The two variants are physically different with the shoots for Muguka and the leaves for miraa being chewed.

In Embu County, we identified two sub-counties (Mbeere North \& Mbeere South) as having high production of Muguka, while in Meru, we selected four sub-counties (Igembe North, Igembe Central, Igembe South and Tigania East) for their high production of Miraa.

Data collection was carried out between the months of September 2015 to December 2015. 


\section{Participant recruitment Sampling of clusters}

Sub-areas (villages) which are the smallest administrative units were the Primary Sampling Unit (PSU) or cluster in this survey. Using the local administration, we listed all sub-areas growing khat in the identified sub-counties.

We then allocated the number of clusters required for each county (Meru and Embu) using income generated annually as a proxy measure and applying square root allocation method. For sub-counties, we determined the number of clusters required using the square root allocation method based on number of sub-areas in the sub-county growing khat.

In each of the Sub-counties, we used a two-stage cluster sampling methodology where the first stage involved selection of required clusters for adults and children using systematic random sampling. In the second stage we used systematic random sampling to uniformly select 10 households from a listing of households in each cluster.

From identified adult clusters, we selected the household head and the lead spouse. From identified child clusters, among the children aged 10-17 years in each selected household, we randomly selected one child by balloting if there were more than one eligible child. In the occasion a household member was found to be unavailable during the first visit, at least two follow up visits on two separate occasions were made to maximize on response. Whenever there was complete failure to get the selected household member, it was captured as a non-response.

\section{Sample size}

Using the Fischer et al. formula and a desired precision of $5 \%$ for the indicator with $95 \%$ confidence, we required a minimum sample size of 385 . Applying a design effect of 2 due to cluster sampling and a non-response rate of $20 \%$ we determined a sample size rounded off to 1000 .

\section{Ethics and consent}

We were granted scientific approvals; SSC number 2888 from the KEMRI Scientific Review Committee (SSC) and the Scientific and Ethical Review Unit (SERU). We then obtained permission to access the study sites from the relevant authorities.

At the household level we sought informed consent from all the adult participants prior to the interview. For participants aged less than 18 years, informed consent was obtained from either their parents or guardians followed by assent by the participant. We informed participants that participation in the study was voluntary and information collected during the study was solely for study purpose. Participants signed written informed consent after detailed explanation of the study purpose. All consents and study documents were in both English and Kiswahili translations. We asked recruited participants to pick the language they preferred for the interview. Trained research assistants conducted interviews in secluded areas to maintain privacy of participants. For participants who required medical attention, we referred them for appropriate medical care.

\section{Variables}

All study questionnaires were forward translated into the local language (Kiswahili) and then back translated into English. Pretesting and piloting of the study tools was undertaken in a different locality from selected clusters for face and content validity. This ensured the content was understandable to the study population (adults and children). Piloting procedure involved administration of the tools by the study clinicians/nurses followed by interviews with participants about their opinions, concerns and challenges about questions asked. Data was collected using a structured face to face interview format using either English or Kiswahili translations depending on the participants' preference.

We used a researcher designed questionnaire to collect data on socio-demographic characteristics of participants as well as specific khat use behaviour. A separate simplified questionnaire was used for children to collect sociodemographic and khat use behaviour.

We used Alcohol, Smoking and Substance Involvement Screening Test (ASSIST) to collect information on other substance use [33].

We then assessed the presence of five types of psychotic symptoms (mania/hypomania, thought control, paranoia, strange experience, and hallucinations) occurring in the past year using the Psychosis Screening Questionnaire (PSQ) [34] . In some instances, to determine the severity of the symptoms we used one follow-up questions after the main probe question for each type of psychotic symptom.

The questions and response options required for the endorsement of each psychotic symptom were as follows:

1. Mania/hypomania: over the past year, have there been times when you felt very happy indeed without a break for days on end? (yes)

1a. Was there an obvious reason for this? (no)

2. Thought control: over the past year, have you ever felt that your thoughts were directly interfered with or controlled by some outside force or person? (yes)

2a. Did it come about in a way that many people would find hard to believe, for instance, through telepathy? (yes)

3. Paranoia: over the past year, have there been times when you felt that people were againstyou? (yes) 
3a. Have there been times when you felt that people were deliberately acting to harm you or your interests? (yes)

4. Strange experience: over the past year, have there been times when you felt that something strange was going on? (yes)

4a. Was it so strange that other people would find it very hard to believe? (yes)

5. Hallucination: over the past year, have there been times when you heard or saw things that other people could not? (yes)

We diagnosed probable psychosis when at least one of the five experiences was selected.

\section{Statistical analysis}

We carried out data analysis using IBM SPSS version 21.0 statistical software and R software. Analysis included descriptive statistics (means, standard deviations \& medians for continuous variables, proportions and frequency distributions for categorical variables). We confirmed distribution characteristics using Kolmogorov-Sminorf test and Exploratory Data Analysis (EDA) for all the continuous data. Student T-test (for normally distributed data) and Mann-Whitney U test (for skewed data) tested for differences in continuous variables between categories of dependent variables. For categorical variables Chi-square and where applicable, we used Fisher's exact probability tests. A $p$-value of $<0.05$ was considered statistically significant. To determine association of psychotic symptoms and khat chewing while controlling for effect of other variables we carried out binary logistic regression analysis.

\section{Results}

After sampling 650 households from 65 clusters (26 in Embu and 39 in Meru) we enrolled a total of 843 participants out of an expected 1000 (313 from Embu and 530 from Meru) resulting in a non-response rate of $16 \%$. Of

Table 1 Distribution of socio-demographic characteristics \& substance use by sex

\begin{tabular}{|c|c|c|c|c|}
\hline \multirow[t]{2}{*}{ Parameter } & \multirow[t]{2}{*}{ Total } & \multicolumn{2}{|l|}{ Sex, $\%$} & \multirow[t]{2}{*}{$P$-value } \\
\hline & & $\overline{M a l e}$ & Female & \\
\hline Age group in years & $(N=829)$ & $(N=395)$ & $(N=434)$ & \\
\hline $10-17$ & 33.8 & 31.6 & 35.7 & $<0.001$ \\
\hline $18-35$ & 28.3 & 22.0 & 34.1 & \\
\hline $36-50$ & 23.6 & 26.3 & 21.2 & \\
\hline$>50$ & 14.2 & 20.0 & 9.0 & \\
\hline Education (Adults only) & $(N=549)$ & $(N=271)$ & $(N=278)$ & \\
\hline Up to primary & 84.7 & 80.8 & 88.5 & 0.017 \\
\hline Secondary & 12.2 & 16.2 & 8.3 & \\
\hline Tertiary & 3.1 & 3.0 & 3.2 & \\
\hline Occupation (Adults only) & $(N=540)$ & $(N=265)$ & $(N=275)$ & \\
\hline Formal \& Self employed & 13.7 & 17.7 & 9.8 & 0.024 \\
\hline Farmer & 79.4 & 75.1 & 83.6 & \\
\hline Casual, domestic \& other & 6.9 & 7.2 & 6.5 & \\
\hline Income (Adults only) & $(N=460)$ & $(N=256)$ & $(N=204)$ & \\
\hline$<5000$ & 35.0 & 23.0 & 50.0 & $<0.001$ \\
\hline $5000-<50000$ & 59.8 & 69.1 & 48.0 & \\
\hline 50000 \& over & 5.2 & 7.8 & 2.0 & \\
\hline Khat use & $(N=831)$ & $(N=396)$ & $(N=435)$ & \\
\hline Chewers & 36.8 & 54.8 & 20.5 & $<0.001$ \\
\hline Non chewers & 63.2 & 45.2 & 79.5 & \\
\hline Tobacco use (Daily or almost daily) & $(N=829)$ & $(N=395)$ & $(N=434)$ & \\
\hline Yes & 13.4 & 26.3 & 1.6 & $<0.001$ \\
\hline No & 86.6 & 73,7 & 98.4 & \\
\hline Alcohol use (Daily or almost daily) & $(\mathrm{N}=829)$ & $(N=395)$ & $(N=434)$ & \\
\hline Yes & 3.7 & 6.3 & 1.4 & $<0.001$ \\
\hline No & 96.3 & 93.7 & 98.6 & \\
\hline
\end{tabular}


these 831 completed the PSQ questionnaire with adults making $66.3 \%(n=551)$ of the participants.

\section{Distribution of socio-demographic characteristics \& substance use by sex}

The median age of participants was 30 years [Interquartile range (IQR) 15-42 years] and ranged from 10 to 78 years.

Over half of the study participants were farmers below 35 years of age and with a lower level of education. Gender comparisons found more males reporting substance use. See Table 1.

Distribution of socio-demographic characteristics, alcohol and tobacco use by khat chewing

The prevalence of life time use of khat was $44.6 \%$ (371 out of 831) while that of current use was $36.8 \%$ (306 out of 831). There was a significant gender difference in khat use with $54.8 \%$ of males and $20.4 \%$ of the females reporting khat use $(p<0.001)$. The rates of khat chewing in children aged between 10 and 17 years was $13.6 \%$. Khat chewing was significantly associated with male sex $(p<0.001)$, younger age (less than $35 \mathrm{yrs)}(p<0001)$, higher level of income $(p<0.001)$ and comorbid alcohol $(p=0.001)$ and tobacco use $(\mathrm{p}<0.001)$. No significant association was seen with level of education and occupation. See Table 2.

\section{Pattern of khat chewing according to gender}

Forty-four percent of the participants had attained the age of 15 years when they first started chewing khat, however of note is that more females $(32.6 \%)$ reported starting to chew khat under 10 years of age compared to males (12.6\%). Nearly half of the khat users reported daily use of khat and chewing between one to three bunches of khat in a sitting. Many (76.7\%) had chewed khat over a 10 year duration. There was a statistically significant difference in the distribution pattern of khat use between males and females based on age at first use $(p<0.001)$, frequency $(p=0.016)$, amount $(\mathrm{p}=0.001)$ and duration of khat chewing $(\mathrm{p}<0.001)$. See Table 3 .

\section{Distribution of socio-demographic characteristics by psychotic symptoms}

The overall rate of at least one psychotic symptom in the study population was $16.7 \%$. Females had a significantly higher rate of reporting compared to males $(p=$ $0.023)$. The age group of young adults reported significantly higher rates $(\mathrm{p}<0.001)$ with paranoid symptoms featuring predominantly (15.7\%). See Table 4.

\section{Distribution of substance use by psychotic symptoms}

Both hallucinations and strange experiences were significantly associated with khat chewing $P$ value 0.0017 and 0.024 respectively. Khat users had higher rates of all symptoms (although not significant) except mania/
Table 2 Distribution of socio-demographic characteristics, alcohol and tobacco use by Khat chewing

\begin{tabular}{|c|c|c|c|}
\hline \multirow[t]{2}{*}{ Parameter } & \multicolumn{2}{|c|}{ Khat chewing } & \multirow[t]{2}{*}{$P$-value } \\
\hline & $n$ & \%Chew & \\
\hline \multicolumn{4}{|l|}{ Sex } \\
\hline Male & 396 & 54.8 & \multirow[t]{2}{*}{$<0.001$} \\
\hline Female & 435 & 20.5 & \\
\hline \multicolumn{4}{|l|}{ Age group in years } \\
\hline $10-17$ & 280 & 13.6 & \multirow[t]{4}{*}{$<0.001$} \\
\hline $18-35$ & 235 & 50.6 & \\
\hline $36-50$ & 196 & 46.9 & \\
\hline$>50$ & 118 & 48.3 & \\
\hline \multicolumn{4}{|l|}{ Education (Adults only) } \\
\hline Up to primary & 465 & 49.2 & \multirow[t]{3}{*}{0.107} \\
\hline Secondary & 67 & 50.7 & \\
\hline Tertiary & 17 & 23.5 & \\
\hline \multicolumn{4}{|l|}{ Occupation (Adults only) } \\
\hline Formal \& Self employed & 74 & 60.8 & \multirow[t]{3}{*}{0.068} \\
\hline Farmer & 429 & 46.4 & \\
\hline Casual, domestic \& other & 37 & 51.4 & \\
\hline \multicolumn{4}{|l|}{ Income (Adults only) } \\
\hline$<5000$ & 161 & 41.0 & \multirow[t]{3}{*}{$<0.001$} \\
\hline $5000-<50000$ & 275 & 55.6 & \\
\hline 50000 \& over & 24 & 79.2 & \\
\hline \multicolumn{4}{|c|}{ Tobacco use (Daily or almost daily) } \\
\hline Yes & 111 & 78.4 & \multirow[t]{2}{*}{$<0.001$} \\
\hline No & 718 & 30.5 & \\
\hline \multicolumn{4}{|c|}{ Alcohol use (Daily or almost daily) } \\
\hline Yes & 31 & 64.5 & \multirow[t]{2}{*}{0.001} \\
\hline No & 798 & 35.8 & \\
\hline
\end{tabular}

hypomania, which is a mood component. Excluding mania/hypomania symptoms, khat users still had higher rates of overall psychosis at $16.7 \%$ compared to $12.8 \%$ for non-users with no significant difference $(p=0.12)$. Daily use of tobacco was significantly associated with thought control, paranoid and hallucination symptoms of psychosis while daily use of alcohol was significantly associated with almost all symptoms of psychosis except manic/hypomanic symptoms. See Table 5. A total of $23(2.8 \%)$ participants were taking other psychotomimetic substances (cannabis 10; inhalants 7; sleeping pills 1; heroin/morphine/pain medicine 4; and a combination of cannabis, sleeping pills \& hallucinogens 1). Statistical evaluation of use of any of the psychotomimetic substances and psychotic-like symptoms of participants, did not show significant associations. 
Table 3 Pattern of khat chewing by gender

\begin{tabular}{|c|c|c|c|c|}
\hline \multirow[t]{2}{*}{ Characteristic } & \multicolumn{2}{|l|}{ Gender, \% } & \multirow{2}{*}{$\begin{array}{l}\text { Total } \\
(\mathrm{N}=306)\end{array}$} & \multirow[t]{2}{*}{$P$-value } \\
\hline & Male $(N=217)$ & Female $(N=89)$ & & \\
\hline \multicolumn{5}{|c|}{ Age when started khat chewing } \\
\hline Under 10 years & 12.6 & 32.6 & 18.3 & \multirow[t]{3}{*}{$<0.001$} \\
\hline Between 10 and 15 years & 39.5 & 32.6 & 37.5 & \\
\hline above 15 years & 47.9 & 34.9 & 44.2 & \\
\hline \multicolumn{5}{|l|}{ Khat chewing pattern } \\
\hline One day per week & 3.3 & 9.8 & 5.2 & \multirow[t]{4}{*}{0.016} \\
\hline 2-3 days per week & 26.3 & 37.8 & 29.6 & \\
\hline 4-6 days per week & 16.3 & 13.4 & 15.5 & \\
\hline Everyday & 54.1 & 39.0 & 49.8 & \\
\hline \multicolumn{5}{|l|}{ Bunches chewed in a sitting } \\
\hline Less than one & 23.0 & 42.0 & 28.5 & \multirow[t]{4}{*}{0.001} \\
\hline Between 1 and 3 & 49.8 & 47.7 & 49.2 & \\
\hline Between 3 and 5 & 10.6 & 6.8 & 9.5 & \\
\hline More than 5 & 16.6 & 3.4 & 12.8 & \\
\hline \multicolumn{5}{|c|}{ Number of years chewing khat } \\
\hline$<$ than 1 year & - & - & - & \multirow[t]{4}{*}{$<0.001$} \\
\hline $1-4$ years & 9.3 & 29.1 & 15.0 & \\
\hline $5-10$ years & 7.9 & 9.3 & 8.3 & \\
\hline$>10$ years & 82.8 & 61.6 & 76.7 & \\
\hline
\end{tabular}

Logistic regression analysis for strange experiences and hallucinations in relation to Khat use

Adjusting for age, sex and tobacco use, the odds of reporting strange experiences was elevated in Khat users at OR, 2.45; 95\%CI, 1.13-5.34. Similarly, khat use was associated with higher odds of experiencing hallucinations (OR, 2.08; 95\% C.I, 1.06-4.08) controlling for sex, age and alcohol use. See Table 6.

\section{Discussion}

The lifetime prevalence of khat use in the study participants was $44.6 \%$. This study found a high overall prevalence of current khat use (36.8\%). This prevalence is comparable to a study in Ethiopia reporting a $37.8 \%$ prevalence of current khat use [35] but lower than rates in recent population based study in Yemen (80\%) [24, 36]. Khat is thought to be a cash crop in this study area, our study findings however show that khat is not only grown for sale but also locally consumed by the residents. Similar to previous khat studies our study found significant gender differences with khat use predominantly being reported in males [37, 38]. Of note is that in our study setting khat is culturally chewed primarily by men. Few studies have reported on khat use in children, though the rates of chewing in children in our study were only $13.6 \%$; low compared to studies earlier done in Yemen [36], it still is a worrisome figure as earlier initiation of substance use is linked to increased risk of drug related morbidity [39, 40].

The overall rates of at least one psychotic symptom reported were slightly higher (16.7\%) compared to a local household based study conducted in Western Kenya (13.9\%) [31]. Varying levels of risk factors particularly exposure to substance use may explain the difference seen. Interestingly however, unlike similar population based khat studies elsewhere [41], we found a significantly higher rate of psychotic symptoms reported in women compared to men; a finding that was similarly observed in a Western Kenya population survey study [31] . Because khat is predominantly chewed by men it is assumed that men would present with higher levels of psychiatric morbidity including psychosis compared to women which is not the case here. One theory could perhaps be a difference in vulnerability to the exposure to khat however, this is unlikely in our study as reported psychotic symptoms were significantly higher in women compared to men regardless of their use of khat. Previous studies have demonstrated an increased stress sensitivity in women compared to men [42, 43]. Of note is that greater stress sensitivity has been significantly associated with increases in positive psychotic symptoms among females [44]. This could offer one explanation to the higher rates of psychotic symptoms seen in women compared to men in our study. This higher reporting of 
Table 4 Distribution of socio-demographic characteristics by psychotic symptoms

\begin{tabular}{|c|c|c|c|c|c|c|c|}
\hline Parameter & $\mathrm{N}$ & $\begin{array}{l}\text { Mania/ Hypomania } \\
\%\end{array}$ & $\begin{array}{l}\text { Thought control } \\
\%\end{array}$ & $\begin{array}{l}\text { Paranoia } \\
\%\end{array}$ & $\begin{array}{l}\text { Strange experiences } \\
\%\end{array}$ & $\begin{array}{l}\text { Hallucinations } \\
\%\end{array}$ & $\begin{array}{l}\text { Any symptom } \\
\%\end{array}$ \\
\hline \multicolumn{8}{|l|}{ Sex } \\
\hline Male & 396 & 2.5 & 3.8 & 7.3 & 3.0 & 4.3 & 13.6 \\
\hline Female & 435 & 3.2 & 4.4 & 11.5 & 5.5 & 7.1 & 19.5 \\
\hline P-value & & 0.551 & 0.673 & 0.041 & 0.079 & 0.080 & 0.023 \\
\hline \multicolumn{8}{|l|}{ Age group } \\
\hline $10-17$ & 280 & 2.5 & 1.8 & 3.2 & 1.4 & 2.5 & 10.4 \\
\hline $18-35$ & 235 & 5.1 & 7.2 & 15.7 & 6.8 & 9.8 & 26.0 \\
\hline $36-50$ & 196 & 1.5 & 4.1 & 8.2 & 4.6 & 4.6 & 13.8 \\
\hline$>50$ & 118 & 1.7 & 3.4 & 14.4 & 5.9 & 7.6 & 18.6 \\
\hline P-value & & 0.105 & 0.020 & $<0.001$ & 0.019 & 0.003 & $<0.001$ \\
\hline \multicolumn{8}{|l|}{ Education (Adults only) } \\
\hline Up to primary & 465 & 3.4 & 5.6 & 13.8 & 6.0 & 7.5 & 21.1 \\
\hline Secondary & 67 & 1.5 & 4.5 & 9.0 & 6.0 & 7.5 & 16.4 \\
\hline Tertiary & 17 & 0 & 0 & 0 & 0 & 5.9 & 5.9 \\
\hline P-value & & nv & nv & 0.151 & nv & 0.968 & 0.225 \\
\hline \multicolumn{8}{|l|}{ Occupation (adults only) } \\
\hline Formal \& Self employed & 74 & 2.7 & 2.7 & 6.8 & 4.1 & 8.1 & 14.9 \\
\hline Farmer & 429 & 3.3 & 5.4 & 13.8 & 6.3 & 7.2 & 20.5 \\
\hline Casual, domestic \& other & 37 & 2.7 & 10.8 & 13.5 & 5.4 & 8.1 & 34.3 \\
\hline P-value & & nv & nv & 0.248 & nv & 0.951 & 0.423 \\
\hline \multicolumn{8}{|c|}{ Income (Monthly income for adults only) } \\
\hline$<5000$ & 161 & 5.0 & 6.2 & 17.4 & 5.6 & 6.2 & 22.4 \\
\hline $5000-<50000$ & 275 & 2.9 & 5.5 & 10.5 & 6.9 & 8.0 & 20.4 \\
\hline 50000 \& over & 24 & 0 & 4.2 & 8.3 & 4.2 & 0 & 8.3 \\
\hline$P$-value & & 0.334 & 0.899 & 0.095 & 0.781 & 0.302 & 0.282 \\
\hline
\end{tabular}

$n v$ Chi-square not valid, ${ }^{*}=$ Fisher's Exact Probability

Table 5 Distribution of substance use by psychotic symptoms

\begin{tabular}{|c|c|c|c|c|c|c|c|}
\hline \multirow[t]{2}{*}{ Parameter } & \multirow[t]{2}{*}{ N } & Mania/ Hypomania & \multirow{2}{*}{$\begin{array}{l}\text { Thought control } \\
\%\end{array}$} & \multirow{2}{*}{$\begin{array}{l}\text { Paranoia } \\
\%\end{array}$} & \multirow{2}{*}{$\begin{array}{l}\text { Strange experiences } \\
\%\end{array}$} & \multirow{2}{*}{$\begin{array}{l}\text { Hallucinations } \\
\%\end{array}$} & \multirow{2}{*}{$\begin{array}{l}\text { Any symptom } \\
\%\end{array}$} \\
\hline & & $\%$ & & & & & \\
\hline \multicolumn{8}{|l|}{ Khat use } \\
\hline Yes & 306 & 2.6 & 5.6 & 10.5 & 6.5 & 8.2 & 18.6 \\
\hline No & 525 & 3.0 & 3.2 & 9.0 & 3.0 & 4.4 & 15.6 \\
\hline P-value & & 0.719 & 0.104 & 0.476 & 0.017 & 0.024 & 0.262 \\
\hline \multicolumn{8}{|c|}{ Tobacco use (Daily or almost daily) } \\
\hline Yes & 111 & 5.4 & 8.1 & 16.2 & 9.9 & 9.0 & 27.0 \\
\hline No & 718 & 2.5 & 3.5 & 8.5 & 3.5 & 5.3 & 15.2 \\
\hline P-value & & $0.089^{\mathrm{a}}$ & $0.028^{a}$ & 0.010 & $0.005^{\mathrm{a}}$ & 0.119 & 0.002 \\
\hline \multicolumn{8}{|c|}{ Alcohol use (Daily or almost daily) } \\
\hline Yes & 31 & 3.2 & 12.9 & 22.6 & 12.9 & 19.4 & 32.3 \\
\hline No & 798 & 2.9 & 3.8 & 9.0 & 4.0 & 5.3 & 16.2 \\
\hline P-value & & $0.605^{a}$ & $0.034^{a}$ & $0.022^{a}$ & $0.041^{a}$ & $0.007^{\mathrm{a}}$ & 0.019 \\
\hline
\end{tabular}

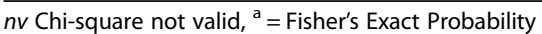

Sex, age group, current Khat chewing, tobacco and alcohol use were subjected to binary logistic regression using backward stepwise (LR) method for strange experiences as well as hallucinations and following tables shows the variables that were retained in the models 
Table 6 Results of Logistic regression analysis for Strange experiences and Hallucinations

\begin{tabular}{|c|c|c|c|c|c|c|c|}
\hline \multirow[t]{2}{*}{ Variable } & \multirow[t]{2}{*}{ Categories } & \multirow[t]{2}{*}{$\beta$} & \multirow[t]{2}{*}{ S.E. $(\beta)$} & \multirow[t]{2}{*}{$p$-value } & \multirow[t]{2}{*}{$\mathrm{AOR}^{\mathrm{a}}$} & \multicolumn{2}{|c|}{$95 \% \mathrm{Cl}$ for $\mathrm{AOR}$} \\
\hline & & & & & & Lower & Upper \\
\hline \multicolumn{8}{|l|}{ Strange experiences } \\
\hline \multirow[t]{2}{*}{ Sex } & Female & -0.752 & 0.231 & $<0.001$ & 5.828 & 2.211 & 15.362 \\
\hline & Male & Reference & & & & & \\
\hline \multirow[t]{2}{*}{ Khat use } & Yes & -0.568 & 0.324 & 0.024 & 2.453 & 1.126 & 5.340 \\
\hline & No & Reference & & & & & \\
\hline \multirow[t]{2}{*}{ Tobacco use } & Yes & 1.048 & 0.292 & 0.001 & 5.903 & 2.095 & 16.636 \\
\hline & No & Reference & & & & & \\
\hline Constant & & -4.935 & 0.520 & $<0.001$ & 0.007 & & \\
\hline \multicolumn{8}{|l|}{ Hallucinations } \\
\hline \multirow[t]{2}{*}{ Sex } & Female & 1.025 & 0.368 & 0.005 & 2.787 & 1.356 & 5.728 \\
\hline & Male & Reference & & & & & \\
\hline \multirow[t]{4}{*}{ Age group in years } & $10-17$ & Reference & & & & & \\
\hline & $18-35$ & 1.044 & 0.462 & 0.024 & 2.840 & 1.148 & 7.023 \\
\hline & $36-50$ & 0.367 & 0.531 & 0.489 & 1.444 & 0.510 & 4.089 \\
\hline & Over 50 & 1.082 & 0.535 & 0.043 & 2.950 & 1.033 & 8.420 \\
\hline \multirow[t]{2}{*}{ Khat use } & Yes & 0.733 & 0.343 & 0.033 & 2.080 & 1.062 & 4.077 \\
\hline & No & Reference & & & & & \\
\hline \multirow[t]{2}{*}{ Alcohol use } & Yes & 1.492 & 0.518 & 0.004 & 4.446 & 1.612 & 12.261 \\
\hline & No & Reference & & & & & \\
\hline Constant & & -4.470 & 0.499 & $<0.001$ & 0.011 & & \\
\hline
\end{tabular}

${ }^{a} A O R$ Adjusted Odds Ratio

psychotic symptoms among females than males is in congruent to findings of the Western Kenya study that examined psychotic symptoms in a general population. Though we did not measure life events in the present study, exposure to life events measured in the Western Kenya study found a significant association between experiencing a life events and reporting of psychotic symptoms. When life events were analysed by sex in the study, 4 individual life events namely serious illness, injury or assault to self, bullying, violence at home and running away from your home were associated with increased risk of having psychotic symptoms in females, while none of the same or other life events were associated with increased risk of having psychotic symptoms in males. This finding further supports the theory of gender difference in stress reactivity.

Regarding psychotic symptom profile, khat using participants were more likely to report experiencing strange events and hallucinations compared to other psychotic symptoms. Other studies have linked khat associated psychosis with mania and paranoid symptoms two symptoms that were not statistically significant in this study [45]. It is worth mentioning that a number of studies have continually shown a high rate of concurrent substance use among khat users [46, 47]. Evidenced also in this study with high rates of concurrent cigarette and alcohol use. Polysubstance use may impact on khat related psychosis symptom profile [48, 49]. Alcohol related psychosis for example is primarily characterized by hallucinations while stimulants more commonly induce paranoid symptoms of psychosis [50, 51].

After combining all psychotic symptoms no significant association was seen with psychosis for khat users. However, when looking at individual psychotic symptoms both the unadjusted and adjusted analysis, khat use was associated with elevated odds of reporting strange experiences and hallucinations. Based on the cross-sectional nature of our study design it is difficult to conclude on what came first, whether khat itself caused psychosis or whether the participants with existing psychotic disorders used khat in an attempt to alleviate psychotic symptoms. Further, as there was no time line provided for the psychotic experiences and khat use in the interview questions, it is possible that khat users experienced these psychotic symptoms only when they were under influence of khat (acute intoxication) and not in a more persistent way. In this study, we set out to look at discrete psychotic symptoms rather than to make diagnoses of psychotic disorders. The psychosis screening items on the PSQ were used for this purpose since the instrument 
has been used in our setting in the past [31], and these are the same questions that would be used to screen for psychotic symptoms in a clinical setting, whether children or adults. Additionally, the items are similar to those in a validated adolescent screening [52]. The strength of this study is the relatively large population size recruited using random sampling techniques. However, our study was conducted in a primarily rural population in eastern Kenya and hence generalizability to other populations is unknown.

\section{Conclusion}

This is the first Kenyan population-based study focusing specifically on khat use. Controlling for alcohol and tobacco use we found psychotic symptoms of hallucinations and strange experiences to be significantly elevated in khat users compared to non-users in this study population. There is need for more epidemiological studies with different study designs to see if similar findings are replicated.

\section{Abbreviations \\ ASSIST: Alcohol, Smoking and Substance Involvement Screening Test; EDA: Exploratory Data Analysis; IQR: Interquartile range; KEMRI SSC: Kenya Medical Research Institute Scientific Review Committee; PSQ: Psychosis Screening Questionnaire; PSU: Primary Sampling Unit; SERU: Scientific and Ethical Review Unit; SPSS: Statistical Package for Social Sciences}

\section{Acknowledgements}

Kenya government for financial support, Meru and Embu Counties leadership for administrative support, research assistants, fieldworkers and laboratory staff for data collection. Last but not least and of importance, all study participants who made the study a reality. We also acknowledge Director, KEMRI for his support.

\section{Funding}

This study was supported by funds from the Government of Kenya Exchequer. The funder did not have any role in the study design, data collection, data analysis, interpretation or writing of the report.

\section{Availability of data and materials}

Datasets used and/or analysed during the current study are available from the first author on reasonable request.

\section{Authors' contributions}

LO, FK, LA, VM and EM co-authored the first draft of the manuscript. EM conducted the statistical analyses and wrote the statistical methods and result section of the manuscript LO, FK, EM, VM, LK, SA, PW, LK, MK, RM, EE, JM, DM, and $\mathrm{CM}$ were involved in the designing of the work and the acquisition of the data. All authors reviewed and approved the final version of the manuscript.

\section{Ethics approval and consent to participate}

The Kenya Medical Research Institute's ethical and review committee approved the study. All eligible study participants aged 18 years and above signed a written informed consent prior to recruitment into the study. Eligible study participants aged 10-17 years gave assent by signing a written assent form. Additional to the assent form the parents/guardians of these participants aged between 10 and 17 years signed a parental permission form to consent their children's participation.

\section{Consent for publication}

Not applicable.

\section{Competing interests}

The authors declare that they have no competing interests.

\section{Publisher's Note}

Springer Nature remains neutral with regard to jurisdictional claims in published maps and institutional affiliations.

\section{Author details}

${ }^{1}$ Kenya Medical Research Institute, Centre for Clinical Research, P.O. Box 54840 00200, Off Mbagathi Road, Nairobi, Kenya. ${ }^{2}$ Kenya Medical Research Institute, Centre for Public Health Research, P.O. Box 54840 00200, Off Mbagathi Road, Nairobi, Kenya. ${ }^{3}$ Moi University School of Medicine, P.O Box 4606, Eldoret 30100, Kenya. ${ }^{4}$ Rongo University College, School of Physical Sciences, Technology \& Engineering, P.O. Box 103-40404, Rongo, Kenya.

Received: 27 September 2018 Accepted: 15 April 2019

Published online: 07 May 2019

\section{References}

1. Berihu BA. Effect of Khat (Catha edulis Forsk) on Neurobehavioral Functions: Systematic review and Meta analysis. Int J Pharma Sci Res. 2015;6:1369-77.

2. Carrier N. Bundles of choice: variety and the creation and manipulation of Kenyan Khat's value. Ethnos. 2006;71:415-37. https://doi.org/10.1080/ 00141840600902737.

3. Carrier N. Is miraa a drug?: categorizing Kenyan khat. Subst Use Misuse. 2008;43:803-18. https://doi.org/10.1080/10826080701739016.

4. Odenwald M, Warfa N, Bhui K, Elbert T. The stimulant khat--another door in the wall? A call for overcoming the barriers. J Ethnopharmacol. 2010;132: 615-9. https://doi.org/10.1016/j.jep.2009.11.005.

5. Musyimi I. Kenya's Intra Africa Horticultural Trade Executive Summary | Horticultural News. Hortinews. 2016. Sector News. http://www.hortinews.co. ke/2016/01/12/kenyas-intra-africa-horticultural-trade-executive-summary/.

6. Cox Glenice RH. Adverse effects of khat obtaining khat in Western countries. Adv Psychiatr Treat. 2003;9:456-63.

7. Douglas H, Boyle M, Lintzeris $N$. The health impacts of khat: a qualitative study among Somali-Australians. Med J Aust. 2011;195:666-9.

8. Berihu BA. Effect of Khat (Catha edulis Forsk) on neurobehavioral functions: systematic review and Meta analysis. Int J Pharma Sci Res. 2015;6:1369-77.

9. Halket JM, Karasu Z, Murray-Lyon IM. Plasma cathinone levels following chewing khat leaves (Catha edulis Forsk.). J Ethnopharmacol. 1995;49:111-3. https://doi.org/10.1016/0378-8741(95)90038-1.

10. Toennes SW, Harder S, Schramm M, Niess C, Kauert GF. Pharmacokinetics of cathinone, cathine and norephedrine after the chewing of khat leaves. $\mathrm{Br} J$ Clin Pharmacol. 2003;56:125-30. https://doi.org/10.1046/j.1365-2125.2003. 01834.x.

11. Widler $P$, Mathys K, Brenneisen R, Kalix P, Fisch H-U. Pharmacodynamics and pharmacokinetics of khat: a controlled study. Clin Pharmacol Ther. 1994;55: 556-62. https://doi.org/10.1038/clpt.1994.69.

12. Hoffman R, Al'Absi M. Khat use and neurobehavioral functions: suggestions for future studies. J Ethnopharmacol. 2010;132:554-63. https://doi.org/10. 1016/j.jep.2010.05.033.

13. Wabe NT. Chemistry, pharmacology, and toxicology of khat (Catha edulis forsk): a review. Addict Heal. 2011;3:137-49.

14. Abdeta T, Tolessa D, Adorjan K, Abera M. Prevalence, withdrawal symptoms and associated factors of khat chewing among students at Jimma University in Ethiopia. BMC Psychiatry. 2017;17:142. https://doi.org/10.1186/ s12888-017-1284-4.

15. Tesfaye F, Byass P, Wall S, Berhane Y, Bonita R. Association of smoking and khat (Catha edulis Forsk) use with high blood pressure among adults in Addis Ababa, Ethiopia, 2006. Prev Chronic Dis. 2008:5:A89.

16. Saif-Ali R, Al-Qirbi A, Al-Geiry A, AL-Habori M. Effect of Catha edulis on plasma glucose and C-peptide in both type 2 diabetics and non-diabetics. J Ethnopharmacol. 2003;86:45-9.

17. Raja'a YA, Noman TA, Al-Warafi AK, Al Mashraki NA, Al Yosofi AM. Khat chewing is a risk factor of duodenal ulcer. Saudi Med J. 2000;21:887-8.

18. Kassim S, Croucher R. Factors associated with dental and medical care attendance in UK resident Yemeni khat chewers: a cross sectional study. BMC Public Health. 2012;12:486. https://doi.org/10.1186/1471-2458-12-486.

19. Mwenda JM, Arimi MM, Kyama MC, Langat DK. Effects of khat (Catha edulis) consumption on reproductive functions: a review. East Afr Med J. 2003;80: 318-23.

20. Feyissa AM, Kelly JP. A review of the neuropharmacological properties of khat. Prog Neuro-Psychopharmacol Biol Psychiatry. 2008;32:1147-66. https:// doi.org/10.1016/j.pnpbp.2007.12.033. 
21. Kalix P, Khan I. Khat: an amphetamine-like plant material. Bull World Health Organ. 1984;62:681-6.

22. Dhaifalah I, Santavý J. Khat habit and its health effect. A natural amphetamine. Biomed Pap Med Fac Univ Palacky Olomouc Czech Repub. 2004;148:11-5

23. Brenneisen R, Fisch HU, Koelbing U, Geisshüsler S, Kalix P. Amphetamine-like effects in humans of the khat alkaloid cathinone. Br J Clin Pharmacol. 1990; 30:825-8. http://www.ncbi.nlm.nih.gov/pubmed/2288828.

24. Odenwald M, Neuner F, Schauer M, Elbert T, Catani C, Lingenfelder B, et al. Khat use as risk factor for psychotic disorders: a cross-sectional and casecontrol study in Somalia. BMC Med. 2005;3:5. https://doi.org/10.1186/1741 7015-3-5.

25. Odenwald M, al'Absi M. Khat use and related addiction, mental health and physical disorders: the need to address a growing risk. East Mediterr Health J. 2017:23:236-44.

26. McLaren P. Khat psychosis. Br J Psychiatry. 1987;150:712-3.

27. Maitai CK, Dhadphale M. Khat-induced paranoid psychosis. Br J Psychiatry. 1988;152:294.

28. Degraeve G. Khat-induced psychosis? Tijdschr Psychiatr. 2007:49:763-7 http://www.ncbi.nlm.nih.gov/pubmed/17929229. Accessed 26 Jan 2018.

29. Alem A, Shibre T. Khat induced psychosis and its medico-legal implication: a case report. Ethiop Med J. 1997;35:137-9.

30. Widmann M, Warsame AH, Mikulica J, von Beust J, Isse MM, Ndetei D, et al. Khat use, PTSD and psychotic symptoms among Somali refugees in Nairobi â€ a pilot study. Front Public Heal. 2014;2:71. https://doi.org/10.3389/fpubh. 2014.00071

31. Jenkins R, Othieno C, Ongeri L, Ogutu B, Sifuna P, Kingora J, et al. Adult psychotic symptoms, their associated risk factors and changes in prevalence in men and women over a decade in a poor Rural District of Kenya. Int J Environ Res Public Health. 2015;12:5310-28. https://doi.org/10.3390/ ijerph120505310.

32. Balint EE, Falkay G, Balint GA. Khat - a controversial plant. Wien Klin Wochenschr. 2009;121:604-14. https://doi.org/10.1007/s00508-009-1259-7.

33. WHO ASSIST Working Group. The alcohol, smoking and substance involvement screening test (ASSIST): development, reliability and feasibility. Addiction. 2002;97:1183-94.

34. Bebbington Paul NT. The psychosis screening questionnaire. Int J Methods Psychiatr Res. 1995;5:11=19 http://psycnet.apa.org/record/1995-39335-001. Accessed 15 Dec 2017.

35. Damena T, Mossie A, Tesfaye M. Khat chewing and mental distress: a community based study, in Jimma city, southwestern Ethiopia. Ethiop J Health Sci. 2011;21:37-45.

36. Basunaid S, van Dongen M, Cleophas TJ. Khat abuse in Yemen: a population-based survey. Clin Res Regul Aff. 2008;25:87-92. https://doi.org/ 10.1080/10601330802064298.

37. Nakajima M, al'Absi M, Dokam A, Alsoofi M, Khalil NS, Al Habori M. Gender differences in patterns and correlates of khat and tobacco use. Nicotine Tob Res. 2013;15:1130-5. https://doi.org/10.1093/ntr/nts257.

38. Nakajima M, Dokam A, Alsameai A, AlSoofi M, Khalil N, al'Absi M. Severity of khat dependence among adult khat chewers: the moderating influence of gender and age. J Ethnopharmacol. 2014;155:1467-72. https://doi.org/10. 1016/j.jep.2014.07.030.

39. Grant BF, Dawson DA. Age of onset of drug use and its association with DSM-IV drug abuse and dependence: results from the National Longitudinal Alcohol Epidemiologic Survey. J Subst Abus. 1998;10:163-73.

40. Chen CK, Lin SK, Sham PC, Ball D, Loh EW, Hsiao CC, et al. Pre-morbid characteristics and co-morbidity of methamphetamine users with and without psychosis. Psychol Med. 2003;33:1407-14.

41. Kotb El Sayed M, Amin H-K. Catha edulis chewing effects on treatment of paranoid schizophrenic patients. Neuropsychiatr Dis Treat. 2015;11:1067. https://doi.org/10.2147/NDT.S81011.

42. Lataster T, Valmaggia L, Lardinois M, van Os J, Myin-Germeys I. Increased stress reactivity: a mechanism specifically associated with the positive symptoms of psychotic disorder. Psychol Med. 2013;43:1389-400. https:// doi.org/10.1017/S0033291712002279.

43. Oldehinkel AJ, Bouma EMC. Sensitivity to the depressogenic effect of stress and HPA-axis reactivity in adolescence: a review of gender differences. Neurosci Biobehav Rev. 2010;35:1757-70. https://doi.org/10.1016/j.neubiorev. 2010.10.013.

44. Gibson LE, Anglin DM, Klugman JT, Reeves LE, Fineberg AM, Maxwell SD, et al. Stress sensitivity mediates the relationship between traumatic life events and attenuated positive psychotic symptoms differentially by gender in a college population sample. J Psychiatr Res. 2014;53:111-8. https://doi.org/10. 1016/j.jpsychires.2014.02.020.

45. Giannini AJ, Castellani S. A manic-like psychosis due to khat (Catha edulis Forsk.). J Toxicol Clin Toxicol. 1982;19:455-9.

46. Kassim S, Rogers N, Leach K. The likelihood of khat chewing serving as a neglected and reverse 'gateway' to tobacco use among UK adult male khat chewers: a cross sectional study. BMC Public Health. 2014;14:448. https://doi. org/10.1186/1471-2458-14-448.

47. Mahfouz MS, Alsanosy RM, Gaffar AM, Makeen A. Tobacco use among university students of Jazan region: gender differences and associated factors. Biomed Res Int. 2014;2014:1-7. https://doi.org/10.1155/2014/279231.

48. Jones JD, Calkins ME, Scott JC, Bach EC, Gur RE. Cannabis use, polysubstance use, and psychosis Spectrum symptoms in a communitybased sample of U.S. youth. J Adolesc Health. 2017;60:653-9. https://doi.org/ 10.1016/J.JADOHEALTH.2017.01.006

49. Connor JP, Gullo MJ, Chan G, Young RM, Hall WD, Feeney GFX. Polysubstance use in Cannabis users referred for treatment: drug use profiles, psychiatric comorbidity and Cannabis-related beliefs. Front Psychiatry. 2013;4:79. https://doi.org/10.3389/fpsyt.2013.00079.

50. Stankewicz HA, Salen P. Alcohol related psychosis. StatPearls Publishing; 2018. http://www.ncbi.n/m.nih.gov/pubmed/29083782.

51. Harris D, Batki SL. Stimulant psychosis: symptom profile and acute clinical course. Am J Addict. 2000;9:28-37.

52. Kelleher I, Harley M, Murtagh A, Cannon M. Are screening instruments valid for psychotic-like experiences? A validation study of screening questions for psychotic-like experiences using in-depth clinical interview. Schizophr Bull. 2011;37:362. https://doi.org/10.1093/SCHBUL/SBP057.

\section{Ready to submit your research? Choose BMC and benefit from:}

- fast, convenient online submission

- thorough peer review by experienced researchers in your field

- rapid publication on acceptance

- support for research data, including large and complex data types

- gold Open Access which fosters wider collaboration and increased citations

- maximum visibility for your research: over $100 \mathrm{M}$ website views per year

At $\mathrm{BMC}$, research is always in progress.

Learn more biomedcentral.com/submissions 